\title{
Falls Among the Elderly and Vision: A Narrative Review
}

\author{
Ray Marks*
}

\author{
City University of New York, School of Health \& Behavioral Sciences, York College, Columbia University, Teachers \\ College, NY, USA
}

\begin{abstract}
Falls among older people are widespread, and can be catastrophic in terms of injury magnitude, quality of life impact, and increased mortality risk. Among a multitude of factors influencing falls risk rates among older people are deficits in vision, and/or their effects on locomotion, balance, and functional ability. This review discusses the above topic, offers insight into what can be done in this realm based on the current body of literature. Sources drawn from leading peer review articles published over the last 30 years using key words: falls, vision, injury, fracture were retrieved and are analyzed and discussed. On this basis, the importance of falls and their prevention, and future clinical and research directives are highlighted. Expected to increase in prevalence falls cause much undue distress and high personal, as well as societal costs. The research literature on vision and falls, despite having major implications, remains limited at best, at present.
\end{abstract}

Keywords: Aging, falls, fractures, gait, prevention, research, risk, vision.

\section{INTRODUCTION}

\section{The Importance of Falls in an Aging Society}

Owing to their widespread occurrence and deleterious impact, falls and their consequences continue to pose a major public health concern among older adults worldwide [1]. Even in the United States (U.S.), a highly advanced developed country, approximately one in three adults over age 65 experiences a fall on an annual basis [2]. Among those who survive, 20 to $30 \%$ have been found to suffer moderate to severe injuries that commonly reduce mobility and limit independence, even after controlling for chronic conditions and functional disabilities at baseline [3]. As well, about two-thirds of first-time fallers will experience a second fall within a six-month period [4], approximately $42 \%$ will result in hospital admissions with a mean length of stay of 11.6 days, and approximately $50 \%$ of fall injury events that occur at home and require hospital admission will result in discharge to a nursing home [5]. Due to these and other complications including fear of falling and dependence [6], the physical, social, and morbidity costs as well as the direct economic costs of treating fall injuries are consequently highly substantial [2]. Additional complications of multiple falls include significantly increased functional disability, and poorer responses to the prevention of nursing home falls [7].

Much research has consequently been implemented to examine risk factors for falls other than age that might be amenable to prevention, and fortunately a vast body of this research shows a number of modifiable factors can explain the high rate of falling among the elderly, both in the community and in the nursing home setting. This is

*Address correspondence to this author at the Department of Health and Behavior Studies, Teachers College, Box 114, 525W, $120^{\text {th }}$ Street, New York, NY 10027, USA; Tel: 1-212-678-3445; Fax: 1-212-678-8259;

E-mail: rm226@columbia.edu important as the incidence of fall-related injuries and deaths, along with the costly disabling consequences of falls to both the individual and society in general are rising along with the average age of current populations such as the United States [8]. Indeed, it would seem imperative, more than ever, to continue to identify and categorize those predisposing risk factors for falls that are amenable to change and to apply this information in an optimal manner to prevent or allay the aforementioned highly deleterious cycle of events, found to be experienced by one third of persons over age 65 , and about one in two over age 80 each year [9].

Focusing on identifying commonplace risk factors for falling seems an especially reasonable idea, because probably fewer than 10 percent of all falls result from overwhelming intrinsic causes such as a loss of consciousness or extrinsic causes such as being hit by a car [10]. Rather, cumulative evidence indicates that among the elderly, factors deemed most likely to contribute to falls and fall injuries are: physical frailty, physical inactivity, alcohol misuse, cognitive and sensory impairments [9], visual impairments and visual cognition [11], neurological and musculoskeletal disabilities, psychoactive medications, and difficulties in gait and balance $[12,13]$, most of which may be somewhat amenable to well-designed remedial interventions. Other factors include the use of inappropriate eyewear [14], the overuse of psychoactive medications [15], comorbid conditions and being underweight [16] or overweight with severe polyneuropathy [17].

In addition, environmental factors such as slippery surfaces, uneven floors, poor lighting, loose rugs, unstable furniture items, and a variety of obstacles and objects on floors may pose further risk of falling and serious injury [17]. Other documented risk factors for falls include a variety of pathologic or disease states of later life leading to sedentary behaviors [18]; health and functional status [19], and individual behavioral factors such as risk taking [20]. 
The failure to seek appropriate assistance from health care professionals and to employ prescribed preventive strategies [21] and the lack of targeted preventive and treatment services and other community resources are specific socioeconomic risk factors [22] that may also influence the risk of falls.

Since the risk of falling increases incrementally with the number of prevailing risk factors [9], falls from multiple physiological risk factors usually result in recurrent falls [23], and since the incidence of fall-related injuries and deaths is rising along with the average age of current populations such as the United States [8], reducing one or more preventable fall-related risk factors might carry with it a proportionate reduction in fall frequency and injury risk [10]. Evidence based strategies to reduce modifiable falls risk factors include physical activity programs to improve strength [24, 25], balance and coordination [26], supervision to minimize the use of psychoactive medications [27], interventions that maximize control of comorbid conditions [27], and environmental assessments and modifications [28]. Others include the use of hip protectors [16], as well as specific shoe types and dietary amendments and supplementation [25]. While mentioned in the research on this topic, much less emphasis has been placed on vision and its impairment as a potent and independent risk factor for falling in people over the age of 60 years [11].

This paper focuses on vision as a risk factor for falls, and reviews relevant research literature on how vision loss, a highly common age associated disability [11], can influence the risk for falls, as well as how efforts to minimize vision loss and promote vision can reduce the risk for falls among community-dwelling older adults.

\section{METHODS}

To derive evidence-based implications for health promotion practices and policy to reduce the burden of falls injuries. CINAHL, COCHRANE, EMBASE, MEDLINE, and PUBMED computerized databases were used to search the research literature concerning falls injury mechanisms, prevalence data, risk factors, and prevention strategies published in English as full reports during 1974-2014. All types of study design were deemed acceptable, as the number of prospective studies remains limited, even though the topic of vision and falls appears to be increasing as a research focus.

Excluded were studies involving children, those that took place in nursing homes, those not related to vision and falls, or if vision was examined as a falls risk correlate but implications were not reported. The focus on falls in the community was adopted firstly because many elders today desire or are encouraged to remain in the community, and this area of fostering life quality for this increasing long-term home dwelling population is very diverse and under studied, while the specific reasons why elders fall in the nursing home environment has been fairly well studied. Keywords for searching included falls, fall injuries, falls prevention, vision, visual impairment, and the terms falls and vision when combined yielded 875 related citations. Many however did not address the question of interest in this present review and were not included. The number of relevant articles selected was 120 .

In addition to research efforts designed to better understand the role of vision in heightening falls risk among community dwelling older adults, we tried to identify published reports on community-based efforts to reduce the risk of falls using multi-factorial approaches, and the degree to which these included vision oriented strategies. Best practices for improving visual acuity, and other reasons for vision challenges in the context of falling were also documented. A narrative approach was adopted due to the great heterogeneity of the research in this area, the numerous descriptive cross-sectional studies, the diverse range of topics studied, the small samples studied, and the presence of very few long-term prospective studies.

\section{RESULTS}

\section{Vision and Falls}

Visual impairments, highly prevalent in the elderly [29] are commonly associated with poor depth perception, which comprises binocular stereopsis or the ability to perceive objects in three dimensions and monocular cues implicating depth and motion cues [30]. They are also associated with a reduced ability to perceive contrast [31], which involves the ability to detect stimuli of varying brightness against a background of given brightness [30]. In this regard, Legood et al. [31] found elderly people with reduced visual acuity, a measure of spatial resolution used for perceiving fine detail [30] were 1.7 times more likely to fall and 1.9 times more likely to have multiple falls compared with fully sighted populations. Moreover, poor distance visual acuity reportedly increased the risk of fractures related to falling $[32,33]$, quite markedly, as did the presence of a visual impairment, in general [34]. Klein et al. [35] similarly noted that the odds ratios for 2 or more falls in the past year for the poorest categories of visual function were $2.02(95 \% \mathrm{CI}$, $1.13,3.63)$ for current binocular acuity and $1.85(95 \% \mathrm{CI}$, $1.10,3.12$ ) for visual sensitivity, and French et al. [36] noted a link between injurious falls, and moderate, rather than severe self-reported visual impairments.

Although difficult to attribute directly to vision, since many confounding factors prevail among the elderly, in light of reasonably compelling evidence in some studies that vision loss increases the risk of frequent falls [37], ReedJones et al. [11] has proposed that impaired vision is undoubtedly an important independent risk factor for falls, albeit an often underreported and underrepresented one in the context of research. This is consistent with earlier observations by Harwood [30] who found poor visual acuity, variously defined, almost doubled the risk of falling. As well, Patino et al. [38] found both central as well as visual peripheral impairments increased the risk for falls and falls with injury after initial examination in a dose-response manner.

In addition to age-related macular degeneration, presbyopia or a problem requiring bifocal corrective lenses, diabetic retinopathy, and glaucoma can all cause various forms of visual impairment that can raise falls risk [11,30]. Lord et al. [39, 40] found that among the reasons why 
limited or disturbed vision may heighten the risk for falls was the use of multi-focal lenses, which can impair distance contrast sensitivity and depth perception, thus reducing the ability of the affected person to detect obstacles or environmental hazards [11]. Similarly the temporary loss of focus on stairs when wearing bifocal lenses can cause misjudgment of depth [30]. Bifocal lenses may also increase the risk for injurious falls in the outdoors because of the increased propensity to trip or estimate unexpected barriers or objects [11].

Limited vision may also have an adverse effect on mobility when negotiating a raised surface such as a step [41], as well as adversely affecting horizontal toe clearance and vertical toe clearance [42], as well as balance [43], and posture control [44] or both, thus potentially increasing the risk of falling when negotiating stairs [45], as well as when walking. This is primarily because the elderly are more dependent on open loop control signals related in part to visual stimuli and influx for purposes of optimizing postural control [46]. As well, the presence of compromised vision can reduce one's ability to respond in a timely and effective way to environmental hazards, as can multifocal spectacles [45], monocular blur and monovision correction contact lenses [42].

Another finding is that many medications can cause visual disturbances that can similarly heighten the risk for falls, as may topical eye medication [30] even if vision is not actually impaired [11]. Glynn et al. [47] who analyzed serious falls determinants among elders with glaucoma and at least one prior fall found the greatest single risk factor for falls was the use of nonmiotic topical eye medications. Other factors associated with the risk of falls were use of miotic eye medications, and visual field impairment, suggesting that ocular and systemic medications are the major predictors of falls even in this elderly population seeking ophthalmologic care for glaucoma, and that certain medications may pose a greater risk for falls than major visual impairment.

It is also reported that severe binocular visual field loss greatly increases rates of falling [48], as does reduced visual acuity [49], which worsens after age 50, regardless of the presence of pathology [30]. Not surprisingly, impaired vision, which affects a high proportion of older individual [50] is found to be an independent risk factor for hip fractures, frequently caused by falls [32], and among the Framingham Study Cohort, the fracture rates in those with moderately impaired vision to poor vision were higher than in those whose vision was considered good [51]. Further, those with moderately impaired vision in one eye and good vision in the other had higher risk of fracture than those with a similar degree of binocular impairment.

Klein et al. [52] found that for persons 60 years of age and older, hip fractures after the age of 40 were significantly related to all measures of visual function, and that time to walk a measured course was significantly related to all measures of visual function. They suggested their findings supported a consistent relationship between falls, fractures, gait time, and visual functions. Specific problems identified by Ivers et al. [53] that influence the risk of hip fracture were binocular visual acuity worse than 20/60, having poor vision in both eyes, having no depth perception, varying degrees of decreasing stereopsis, self-reported poor vision, not wearing glasses at the time of the fall, and increasing time since the last eye examination.

Close et al. [54] who assessed visual acuity with a Snellen chart, defined impaired vision as present where acuity was $6 / 12$ or worse in either eye, or being partially sighted if corrected vision in both eyes was $6 / 24$ or worse, or being blind if acuity was $6 / 60$ or worse in both eyes. Poor binocular vision was defined as a disparity in acuity between the visual acuity of the eyes. Results showed 89 (59\%) patients had visual impairment, and $94(62 \%)$ had poor stereoscopic vision, and $53(35 \%)$ had cataract formation in one or both eyes. Patients were 65 years and older, living in the community, who had presented to an accident and emergency department with a fall history.

In a retrospective case control study by Kantayaporn [55] that aimed to identify the factors of a fall that caused fractures including, gender, underlying diseases, chronic drug use, history of parent fragility fracture, age of menopause, steroid used, body mass index, visual acuity and a timed get up and go test, multivariate regression analysis of 336 cases of fractures in 1,244 cases of fall showed significant factors for the falling and fracture group that were different from falls without a fracture group. These factors included age, female gender, menopause before age 45 and visual impairment. In addition, visual impairment was the key factor other than osteoporosis implicated in falls that resulted in fractures. The author suggested that fracture prevention programs for the elderly should include attention to the correction of any prevailing visual impairment, not only osteoporosis related treatments.

Salonen and Kivela [23] who examined the evidence concerning poor depth perception/stereo acuity and poor low-contrast visual acuity as risk factors of recurrent falls found this quite convincing. Risk factors identified were discrepant vision, a decrease in visual acuity, and loss of visual field, although the results concerning the relationships between poor visual acuity and poor contrast sensitivity and the risk of recurrent falls were less clear.

Skalska et al. [56] who examined factors influencing falls risk among Poles, found visual impairment to be more frequent in fallers 55-59 years of age and 65 years and older. In the younger group, moderate vision impairment was found in $31.05 \%$ of non-fallers and $39.57 \%$ of fallers, and significant visual impairment or blindness was diagnosed in $0.35 \%$ of non-fallers and $1.69 \%$ of fallers $(\mathrm{p}=0.003)$. In the older non-fallers moderately impaired vision was present in $39.45 \%$ of cases studied and severe vision impairment was present in $1.67 \%$ of cases, while in fallers, the rates were $44.85 \%$ and $3.36 \%$, respectively $(\mathrm{p}=0.0002)$. A higher frequency of vision impairment in fallers was found in both genders. That is, moderate vision impairments were found in $41.31 \%$ of men and $44.76 \%$ of women, and severe impairments were found in $3.10 \%$ of men and $2.98 \%$ of women, compared to rates among non-fallers where moderate and severely impaired vision was present in $37.15 \%$ and $1.15 \%$ of men and $36.21 \%$ and $1.28 \%$ of women. In both age groups, the authors found falls occurred more frequently in subjects with impaired vision, and the percentage of fallers increased with the severity of impairment. 
French et al. [36] who analyzed injurious falls and related self-reported incapacities found an increased odds of injurious falls with moderate visual impairment. The observation that moderate but not severe visual impairment was predictive of a past fall was noteworthy. The authors felt that those with more severe impairment might be more cautious than those with less severe vision impairments. They also suggested that visual dysfunction, is not a single sensory problem, but may be more complex than this and can contribute to falls through a number of different mechanisms. This is consistent with findings of Nagamutsu et al. [57] who noted altered visual-spatial attention to taskirrelevant information was associated with heightened falls risk among older adults.

Yet, even though poor vision has been associated with frailty in the elderly, and an increased risk of falls and sustaining a fracture [50], and vision impairments can be both independent or co-occurring risk factors for fall [58], the presence of a visual impairment may go undetected, as far as being a possible risk factor for future falls, and guidelines for preventing falls generally only focus on vision in a very limited way, even though some of these conditions are treatable [50]. Moreover, few focus on visual cognition as a separate or co occurring risk factor despite increasing evidence that this function plays a key role in motor processing and anticipation [11]. In terms of falls-related prevention programs, Gillespie et al. [24] who examined the efficacy of randomized controlled trials of interventions designed to minimize risk factors for falls among the community-dwelling, including the institutionalized and hospitalized elderly, noted that providers contemplating implementation of falls-prevention programs should first consider screening the "at-risk" elderly, and then follow this with intervention programs designed to reduce the risk of falling due to both individual intrinsic and extrinsic causes.

In this respect, understanding what components of vision are most likely to be responsible for increasing the risk for multiple falls [37], as well as other factors that can cause poor vision such as incorrect prescription lenses, scratched lenses, not wearing glasses when needed, the inability to afford lenses, health issues such as diabetes, and vascular abnormalities should be evaluated. While, peripheral vision is reportedly of great importance, especially in outdoor activities, that involve walking in a crowd, in traffic, and on level or irregular ground [58], the most important visual risk factors are said to be reduced contrast sensitivity and depth perception [40]. Multifocal lenses and bi focal glasses may likewise heighten the risk for falling as a result of a reduction in the ability to detect environmental hazards [40, 59]. As well, these individuals may not be able to see a poorly lit bottom step, may not notice surface changes from a carpet to slippery tiles, and their protective responses such as grabbing a rail may be hindered [59].

Unsurprisingly, compared to those without vision impairments Legood [31] found those adults with visual impairments to be seven times more likely to fall and incur serious injury. Reasons for vision deficits include ocular conditions such as diabetic retinopathy, glaucoma, and cataracts. These impairments and others can produce moderate to severe visual impairments that can affect central vision acuity and peripheral vision or both [29], and along with environmental factors such as difficulties in color vision, when perceiving pastel and dark colors, may compromise the ability to judge distances and obstacles or irregularities in the visual field. This is because in many public areas, where pastel colors are used, it may be difficult to detect differences between various surfaces, thus increasing the risk for falls [58].

Although Cummings et al. [60] comprehensive vision and eye assessment, followed by treatment did not reduce falls risk, and may have increased this, strategies that may be helpful for minimizing falls risk among older persons in the community include the timely assessment of visual acuity, contrast sensitivity, and depth perception [61], corrective eye surgery, the prescription of appropriate eyewear, changing glasses, and selected pharmacologic and environmental assessments and interventions [29, 61]. Others have stressed the importance of assessing factors such as visual attention, visual processing, and visual-spatial ability that influence mobility and obstacle avoidance, followed by appropriate treatment, and in cases where it is impossible to reverse the presence of pathology, and restore normal vision, the main aim should be to prevent deterioration [30]. Others who have examined current binocular vision, best-corrected vision, near vision, contrast sensitivity, and visual sensitivity or threshold, recorded using perimetry [35], have suggested that any form of visual impairment may increase falls risk, and since falls risk increases as visual impairment worsens, measures to optimize vision along with the visual environment may be helpful [30]. In addition to correcting refractive errors [53], and possible cataract surgery where indicated [30], the use of single rather than multifocal glasses may help to reduce falls risk [40]. As well, the use of bright colors and contrasts and taking into account the elderly may have red-green vision defects may be helpful when planning public facilities and spaces [58]. Tinetti [62] also discussed the possibility that public health-mandated changes in the environment, such as high-contrast curb and stair markers in public places may prove helpful. As well, appropriate advice about the use of multifocal lenses when walking, and more thought to what would constitute safe and appropriate floor patterns for visually impaired older people might prove useful as well.

Day et al. [63] who did compare a group based exercise, home hazard and vision improvement strategies over a 15 week period, observed that only the exercise intervention had an effect, and although it appeared the intervention improved vision, an increased falls risk was observed. However, numbers actually treated for vision impairments were very low and a clear multidisciplinary approach was not followed. Similarly, simply introducing vision screening for frail older people may not lead to improvements in vision, and hence used in isolation, may provide no direct influence on falls risk, unless more comprehensive approaches, as well as more specific analyses of any prevailing visual problems are forthcoming [64]. In more recent attempts to reduce falls risk, the specific role of vision was not mentioned implicitly, however $[65,66]$.

Clemson et al. [67] conducted a program called The Stepping On program that included regular visual screening, and making adaptations to low vision, among other interventions to reduce falls among the elderly. The 
intervention group experienced a $31 \%$ reduction in falls, which was deemed clinically significant. In another study, Lord et al. [68] examined whether an individualized falls prevention program comprising exercise, visual, and counseling interventions could reduce physiological falls risk and falls among older people. In this study, 620 people aged 75 and older received individualized interventions comprising exercise and strategies for maximizing vision and sensation; while the minimal intervention group received brief advice; and the control group received no intervention. Results showed subjects assigned to the extensive visual intervention group showed significant improvements in tests of visual acuity and contrast sensitivity. The rate of falls and injurious falls within the trial period were similar in the three groups, however.

Thus, while several studies support a compelling case on theoretical grounds for the potential efficacy of visual oriented interventions in preventing falls and fall-related injuries larger and more well-controlled prospective studies of the community-dwelling elderly at "high risk" for falls that clearly provide tailored vision related interventions such as that by Haran et al. [69] and Fitzharris et al. [70] are needed to establish whether these are efficacious or not. Furthermore, even though Guidelines for the Prevention of Falls in Older Persons have recently been developed under the auspices of the American Geriatrics Society (2001)[20], very few of these guidelines provide insight into how vision interventions and assessments might prove helpful, and vision was not listed as an intrinsic risk factor in a recent review of falls in the elderly [71]. Perhaps more focused comprehensive assessments of vision and actual mobility and postural tests would be helpful for assessing those at risk for falling. This is because altering vision alone may not be sufficient for fostering integrated functional strategies needed in the real world for avoiding hazards.

\section{VISUAL CONTROL OF BALANCE AND LOCO- MOTION-AND FALLS}

There are many examples in the research literature that show vision and vision cognition including visual attention, visual spatial ability, and visual processing [11] play an anticipatory role in locomotion [72], and in planning an appropriate motor response [11]. These visually derived adjustments in turn are linked to basic locomotor programs by the motor cortex and interconnected parietal and cerebellar areas [73], and normally result in the regulation of step length and speed, which may be reduced, disrupted, or compromised in the presence of reduced visual input [74].

Impaired vision and uncorrected refractive error can also affect balance [75], spatial-updating of position [76], and postural sway [30] adversely thus increasing the risk for falling [40], especially in those with reduced distant contrast sensitivity and a measure of depth perception called stereopsis. According to Gibson [77], this is because the eye registers the flow pattern of the optic array as well as the static pattern of the array, and this flow pattern in turn, provides for visual kinaesthesis or 'feedback' about the environment which can be used to control and guide exploratory locomotor behavior and may influence interneurones responsible for gait. Moreover, visual mechanisms for correcting sway are increasingly important for the elderly where those of the muscles and tendons decline with age, but these reaction times are generally slower than those of muscle and tendon and may be significantly increased in the elderly person with a vision problem [30]. In addition, research shows that individuals with low vision often have difficulties adapting to extreme lighting levels, environmental obstacles or challenges, complex walking surfaces, and walking in unfamiliar areas, and may lack the ability to judge distances and spatial relations accurately and in a timely way, thus increasing the risk for falls [40].

Furthermore, although Thompson [78] argued that it may be unnecessary to pick up visual information during substantial parts of any locomotor act; and that this information may only become critical in the final stages of the movement when precision is required, a study of longjumpers [79] showed visually directed corrections must be made three to four strides before stride adjustments are required. In addition, Laurent and Thomson [72] showed that well-coordinated visual regulation depends on intermittent information being available over the last three strides as a target is approached.

Patla [80] who agreed that accuracy in modulating step length is partially dependent on the timing of the visual cue, found that later cuing introduced greater variability among subjects in step length adjustments, and that the larger the adjustment required, the greater the destabilizing effect.

These data support results of work by Lee et al. [79] who concluded that certain features/invariants of the optic array must be present for the precise timing required to be successful in various target/obstacle avoidance tasks. This premise was further supported by Patla [81] who reported that in clearing obstacles subjects tended to be more successful if cued earlier rather than later. Unsurprisingly, according to a multivariate model, a history of recurrent falling, coupled with trouble with vision when moving, was observed by Iinattiniemi et al. [82] in a population of homedwelling subjects aged 85 years or older followed prospectively.

According to Laurent and Thompson [72] key factors found to alter co-ordination and effective breaking during a locomotor task are the availability of peripheral visual information, the amount of visual information available, the subjects level of skill, the features of the task, the subject's breaking power and the prevailing speed information. The importance of peripheral visual cues for maintenance of locomotor equilibrium during fast walking over a narrow beam has also been demonstrated [83]. As outlined by Lord [40], the ability to accurately perceive and process visual stimuli has a profound influence on balance, the ability judge distances and spatial relations, and the ability to detect obstacles or hazards in a timely way. Harwood [30] reports vision may also contribute to poor stability in cases with dementia due to loss of visual fixation, and that instability in vestibular disease may have a visual component because the vestibular-ocular reflex helps stabilize retinal images during motion. Earlier, Lord et al. [39] found that whereas visual acuity and contrast sensitivity were not associated with body sway when older subjects stood on a firm base, when placed in a destabilizing situation, body sway and poor visual acuity and contrast sensitivity were significantly correlated. There was also a difference in contrast sensitivity between those 
who fell one or more times in a year of follow-up and those who did not fall. It also appears that reduced vision may be a predisposing factor to postural imbalance and falls in elderly persons.

According to Black et al. [84] a major portion of visual information is used to guide lower limb movements, foot placement, and obstacle detection, which may be important in relation to attempts to reduce falls in the elderly. In particular, a loss of the inferior field of vision region in particular is an important predictor of prospective falls, as is blurred vision [85].

Uemura et al. [86] studied whether an impairment in visual-spatial attention that can cause difficulties in planning and guiding movements, can lead to falls in older adults. They examined the relationship between visual-spatial attention during movement and the risk of falling in 36 older adults, mean age 73 years who performed a rapid choice stepping task in response to flanker task stimuli. Step errors in congruent or incongruent conditions were recorded as a measure of the accuracy of the choice stepping outcome. The four clinical measurements assessed were: 10-min walking time, the timed up and go test, the functional reach test and a 5- chair stand test. The authors found high-risk participants had a significantly higher rate of step errors in the incongruent condition than low-risk participants $(p=0.032)$. Step error in the incongruent condition was the only independent variable which remained significant in the final step of a logistic regression analysis. Although patients with central vision loss, are said to adopt a cautious gait strategy during tasks that present a high risk of falling [87], it was concluded by Uemura et al. [86] that impaired choice stepping in response to a visual-spatial attention-demanding task was associated with the risk of falling in older adults.

Barrett et al. [76] examined the role of vision in spatial updating and its potential contribution to an increased risk of falls in older healthy and fall prone adults using a path integration task. Specifically, the participants had to undertake a triangle completion task in which they were guided along two sides of a triangular route and were then required to return, unguided, to the point where they had begun. During the task, participants could either clearly use full vision to view their surroundings or wore translucent goggles to reduce visuo-spatial information. Performance on the path integration task was assessed by calculating the distance and angular deviation from the participant's return point relative to the starting point. Gait parameters for the unguided walk were also recorded. The authors found equal performance outcomes across groups on all measures for the full vision condition. In contrast, in the reduced vision condition, where participants had to rely on interoceptive cues to spatially update their position, fall-prone older adults made significantly larger distance errors relative to healthy participants. The findings suggested fall-prone older adults, may have greater difficulty in reweighting other sensory cues for spatial updating when visual information is unreliable.

By taking some of this research into account it seems the earlier the required locomotor adaptations are visually identified, the greater appears the liklihood of a successful and economic adaptation. In addition the larger the magnitude of adjustment required, the greater the liklihood of adjustment accuracy, if the visual information is processed during the period when the foot is in contact with the ground. For self-paced movements, intermittent visual sampling may be sufficient to ensure accuracy of movement, but during rapid movements however, consistent vision is desirable to prevent movement inaccuracy.

Table 1 provides an overview of differences in visual and locomotor adaptations with and without impaired vision, regardless of cause.

\section{DISCUSSION}

In light of the growing proportion of the elderly in the United States and other developed nations, the consequences

Table 1. Table describing the importance of vision in the realm of locomotor safety.

\begin{tabular}{|l|l|}
\hline Intact Vision enables- & Timely and safe gait adaptations \\
& Effective balance strategies \\
& The ability to detect surroundings \\
& Adaptions to different ambient lighting situations \\
& Adaptations to altered surface characteristics \\
& Ability to safely negotiate stairs and steps [109] \\
\hline Impaired Vision results in & Modified gait \\
& Reduced visual attention \\
& Reduced ability to identify hazards [59] \\
& Slow vision reaction times [98] \\
& Increased vertical toe clearance variability [74] \\
& More unsafe locomotion \\
& Disruption of the timing and magnitude of stepping adjustments [74] \\
& Less postural stability [103, 105] \\
& Greater difficulty reweighting other sensory cues for spatial updating [76] \\
& Challenges due to obstacles, uneven surfaces, stairs \\
& Diminished protective responses, such as grabbing a rail [59] \\
& Overreliance on visuo-spatial information for spatial cognition but fail to adjust behavior adequately when this information \\
& is unreliable [104] \\
\hline
\end{tabular}


of falls among the elderly, and the documented potential for preventing both the number and severity of injuries due to falls [1], we believe more attention to the role of vision and visual impairment or disruption, highly prevalent in this age group, is highly relevant in efforts to minimize falls risk among the elderly.

However, even though Coleman et al. [88] found severe binocular visual field loss due primarily to cataracts, glaucoma, and age-related macular degeneration explained $33.3 \%$ of the falls among women who fell frequently, and loss of vision increased falls frequency [37], with few exceptions vision is not always routinely assessed and concerted high-quality collaborative efforts to systematize the collection of vision problems in the context of fall-injury surveillance data are sadly lacking, despite increasing evidence that poor depth perception and poor low-contrast visual acuity are risk factors for recurrent falls [23]. Even when measured, Davidson et al. [89] and Close et al. [54] did not provide any treatment related information regarding their referral rates for visual assessments.

In addition, guidelines for preventing falls in older people do not necessarily contain references to improving visual function [90], and health practitioners do not necessarily always address the complexity of vision and its role in falls, and the fact that different aspects of visual functioning may have different relationships to falling and fractures [91], even if they recommend vision checks [92, 93], or optimizing vision [94] or interventions related to vision [95], and regular eye exams and up to date corrective lenses [11]. That is, they do not always assess the vision of their older patients, and even if they do, they do not necessarily clearly understand the link between vision and falls, and vision and function, and vision and balance, and that some intervention strategies may increase rather than decrease the risk of falls. On the other hand, vision screening alone did not lead directly to improved vision according to research by Chou et al. [96], and while appropriate counselling, plus the provision of single lens glasses for older wearers of multifocal glasses who take part in regular outdoor activities is an effective falls prevention strategy, the intervention may be harmful, in those multifocal glasses wearers who pursue low levels of outdoor activity [69].

Given that visual field loss is the primary vision component that increases the risk of falls and the importance of visual field deficits in the risk of falls due to its adverse effects on mobility and increased risk of bumping into obstacles or tripping with worsening visual field function [97], and the increased falls risk among those with macular degeneration with increasing age as a result of diminished vision, visual processing speed, and balance [98] as outlined in Table 2, the wide implementation of screening programs for identifying those elders who are clearly at risk for single and recurrent falls, as a result of one or more visual issues through well-organized and managed health screening centers is highly recommended [99]. In addition given that among those older adults with age-associated macular degeneration where increased visual impairment is significantly associated with an increased incidence of falls and other injuries, and reduced contrast sensitivity is significantly associated with both increased rates of falls and other injuries, while reduced visual acuity was only associated with increased fall rate [49], very careful assessments are desirable in efforts to optimize outcomes, while minimizing costs.

In light of this complexity, the failure to accurately identify the specific visual impairments of the individual, as well as other risk factors for falls, and poorly designed care plans that are not carefully tailored efforts to maximize vision, including visual training [11], may hence prove suboptimal for improving the outcomes of either individual patients. Such efforts among those who have never fallen, as well as among those who have a history of falls, those undergoing cataract surgery, and among younger adults, not only older adults may however, be highly influential in minimizing falls risk and should be made a high priority.

Similarly, despite mounting evidence suggesting that assessments of home environmental risk factors and their remediation can abate the incidence and severity of falls injuries [63], these ideas for taking preventive actions to reduce falls, will not be as effective as they might be for those with visual problems, if these are not assessed and targeted accordingly in and outside the home, and account for the activity level and practices of the individual. Moreover, they are unlikely to succeed without the incorporation of visual training coupled with physical activities such as balance, and exercises that can improve mobility and function, as well as instructional training on where to look when walking or stepping [11].

Policy also needs to support research on the value of introducing a multidisciplinary approach to assist with minimizing falls risk, including support for environmental modifications, visual aid requirements, vision consultations and surgery, as required and sustainable support services. The value of careful planning of public spaces, coverage for eye exams and remedial interventions, and individualized interventions to reduce potentially modifiable vision related risk factors for falling, such as poor lighting and inappropriate eyewear, poor health status, and modifiable environmental risk factors should also be examined in large scale prospective studies with individuals of varying degrees of visual dysfunction.

Since approximately half of the community-dwelling population older than 85 years of age will fall each year [9], and falls are a highly important cause of excess mortality and morbidity in older people [100], the specific needs of those with any evidence of a visual impairment should receive more attention. In particular, although fewer people below age 85 living in the community fall each year, with only a relatively small proportion of fallers experiencing multiple falls, the link between vision impairments and falling and other injuries is compelling and should not be underestimated. Identifying those at increased risk for falling because of vision problems, which may also be more severe if the individual has other sensory impairments [101], a history of previous falls, chronic diseases, and multiple medication use [100] should clearly constitute an essential component of any future fall risk-abatement strategy if we are to reduce the high mortality and morbidity rates associated with falls. In addition, more thought to the type of visual impairment that is observed, along with patient education and appropriate care plans that follow will undoubtedly help to reduce falls risk among those with 
Table 2. Summary of diverse array of studies focusing on falls risk and vision extracted from Pubmed over the past 5 years, many stressing support for efforts to include vision screening among community based elders receiving or seeking primary care.

\begin{tabular}{|c|c|c|c|c|}
\hline Study & Design & Participants & Measures & Results \\
\hline Wood et al. [49] & Prospective & $\begin{array}{l}76 \text { community dwellers with } \\
\text { AMD }\end{array}$ & Monthly falls rates & $\begin{array}{l}74 \% \text { experienced fall/nonfall related injury } \\
\text { Reduced contrast sensitivity and visual acuity } \\
\text { were associated with increased falls rate. } \\
\begin{array}{l}\text { Among older adults with AMD, increased } \\
\text { visual impairment is significantly associated } \\
\text { with increased falls rates }\end{array}\end{array}$ \\
\hline Skalska et al. [56] & Retrospective & $\begin{array}{l}\text { Adults age range 55-59, and } \\
65+\end{array}$ & Falls prevalence & $\begin{array}{l}\text { Sensory impairments such as vision } \\
\text { May increase falls risk }\end{array}$ \\
\hline Timmins [87] & Cross-sectional & $\begin{array}{l}10 \text { patients with central field } \\
\text { vision loss; visual normal }\end{array}$ & Obstacle crossing & $\begin{array}{l}\text { Patients with impaired vision used a cautious } \\
\text { gait strategy during challenging tasks, but not } \\
\text { under less hazardous tasks }\end{array}$ \\
\hline Yip et al. [100] & Cross-sectional & 8317 eye study cases & Health, vision, falls & $\begin{array}{l}25 \% \text { had fallen in past year } \\
\text { Poorer vision was associated with higher } \\
\text { percentages of falls } \\
\begin{array}{l}\text { Self reported vision was a stronger predictor } \\
\text { than actual vision }\end{array} \\
\begin{array}{l}\text { Self-reported vision is a proxy measure of } \\
\text { future falls }\end{array}\end{array}$ \\
\hline To et al. [102] & Prospective & 413 cataract surgery patients & Self-reported falls & $\begin{array}{l}\text { Bilateral cataract patients have increased post } \\
\text { surgical falls risk }\end{array}$ \\
\hline Ellison et al. [108] & Cross-sectional & 31 healthy older adults & $\begin{array}{l}\text { Prismatic } \\
\text { displacement }\end{array}$ & $\begin{array}{l}\text { New glasses resulting in excessive } \\
\text { magnification changes may increase falls risk }\end{array}$ \\
\hline Barrett et al. [111] & Cross-sectional & $\begin{array}{l}\text { Older fall-prone and healthy } \\
\text { adults }\end{array}$ & $\begin{array}{l}\text { Spatial updating } \\
\text { ability }\end{array}$ & $\begin{array}{l}\text { In the reduced vision condition, fall-prone } \\
\text { adults made larger distance errors than health } \\
\text { adults, suggesting greater difficulty in sensory } \\
\text { cue reweighting when visual information is } \\
\text { unreliable }\end{array}$ \\
\hline Black et al. [112] & Cross-sectional & 10 healthy older adults & Visuomotor control & $\begin{array}{l}\text { Step accuracy is diminished for low visibility } \\
\text { targets, and for high levels of refractive blur }\end{array}$ \\
\hline $\begin{array}{l}\text { Meuleners et al. } \\
{[113]}\end{array}$ & Retrospective & Adults age 60 plus, 2 years & Falls risk & $\begin{array}{l}\text { Risk of falling doubled between } 1^{\text {st }} \text { and } 2^{\text {nd }} \\
\text { surgery, before and after cataract surgery, } \\
\text { there is increased risk of serious falls post } \\
\text { cataract surgery which is greater after second } \\
\text { surgery }\end{array}$ \\
\hline Yoo [116] & Cross-sectional & 411 Koreans 65 yrs & Fall numbers & $\begin{array}{l}\text { Recurrent falls were partially predicted by } \\
\text { reduced vision }\end{array}$ \\
\hline
\end{tabular}

vision impairments, as outlined by To et al. [102] who found adults with bilateral cataracts were at high risk of falls and in need of falls prevention interventions. They also recommended ophthalmologists and health professionals to consider contrast sensitivity measures when prioritizing cataract patients for surgery and assessing their risk of falls.

However, this means making investments in training community-based personnel not only to routinely implement and evaluate specific screening and intervention strategies that have been identified as best practices, but to develop patient specific targeted interventions. Such strategies might include, falls-related health education, counseling, physical activities, group activities, as well as efforts to correct central vision and/or peripheral visual components [38] where indicated (see Box 1). Other forms of intervention that have the potential to reduce individual-level risk of falling, such as visual training that can improve spatial cognition are recommended as well [11] and exercise, reducing risk-taking behaviors [84], and increasing the awareness among practitioners of the link between vision loss and falls, and identifying opportunities to reduce hazardous environmental 
factors [84]. The implementation of careful assessments to examine what necessary equipment and environmental modifications are needed both in and outside of the home and training or employing highly qualified skilled personnel to appropriate these changes must also receive support.

Box 1. Examples of prevention strategies that might be helpful in preventing falls among the elderly with visual impairments.

- Appropriate referral for evaluation of other falls risk factors
- acuity
- Correct spectacle prescriptions
- Coeck vision and glasses after a fall
- Instruction on careful use of new lenses
- Keeping spectacles clean
- Maintaining optimal eye health
- Maintaining optimal nutrition and health status
- Removal of environmental hazards
- Providing good lighting and adding highly contrasting colors in
- Inbulatory environments
- Promoting visual attention and cognition
- Regular eye exams
- Medication checks
- Visual training
- areas used by older persons

\section{CONCLUSION}

Because more than a million people suffer from a slip, trip, or falling injury each year, falls have come to be recognized as a major threat to the safety, health and independence of elderly persons. In an aging society, having a heightened awareness of various factors associated with falls in elderly persons and a better understanding of some of the methods of preventing falls seems essential. Even if not all studies support a vision impairment falls linkage, the foregoing review and discussion suggests that systematic efforts to implement risk assessment and intervention strategies that utilize a combination of intervention elements for preventing falls and fall-related injuries that include vision related factors is more likely than not to have several important social and economic implications. This is because firstly, such efforts can lead to more efficient use of limited societal resources. Second, such efforts are likely to reduce morbidity and mortality rates attributable to falls among community-dwelling elderly at high risk for falling, thus improving functional status and promoting independent living. Third, the application of improved efforts to maximize vision, and to minimize the degree to which environmental factors and partially mediating risk factors such as functional limitations, and type of visual aid, may increase falls risk among those with limited vision, an individual's risk of falling may be vastly reduced as outlined by Keay et al. [106], Steinman et al. [107], and Ellison et al. [108].
To prevent falls and their very serious consequences for older adults, especially the frail older person [109], more efforts to routinely encourage practitioners to screen for this important potential serious health risk factor are surely strongly indicated, despite conclusive evidence of a vision falls cause effect linkage [110]. In addition to applying what has been gleaned from studies of vision and visuomotor control in healthy older as well as visually impaired adults [e.g., 111-114, See Table 1], which aspects of vision are most predictive of falls and visual function among elderly fallers and non-fallers [115], what is the link between vision and recurrent falls $[116,117]$, and what should be done to maximize vision in public spaces should especially be examined. The role of exercise in preventing falls injury as well as in improving vision directly should also be explored further in the future.

Meantime, to reduce falls risk, recurrent falls, and fractures related to falls among the elderly, validated vision assessments should be routinely applied in primary care settings and others, including depth perception [118], and recommendations for intervention after that should be tailored and consistent with the activity requirements of the patient, and provided by a highly skilled team of rehabilitation specialists, opthalmologists and physicians, even if other factors are stronger predictors of future falls [119]. To examine the best instrument for screening purposes, more studies concerning the relationships between different measures of vision and the risk of subsequent falls are strongly indicated [23], as are prospective studies of single versus multiple component interventions to prevent primary and recurrent falls as outlined by Timmins et al. [87], Yoo [116], Haran et al. [69] and Klein et al. [120].

\section{CONFLICT OF INTEREST}

The authors confirm that this article content has no conflict of interest.

\section{ACKNOWLEDGEMENTS}

Declared none.

\section{REFERENCES}

[1] Cesari M, Landi F, Torre S, et al. Prevalence and risk factors for falls in an older community-dwelling population. J Gerontol A Biol Sci Med Sci 2002; 57(11): M722-6.

[2] Soriano TA, DeCherrie LV, Thomas DC. Falls in the communitydwelling older adult: a review for primary-care providers. Clin Interv Aging 2007; 2(4): 545-54.

[3] Dunn JE, Rudberg MA, Furner SE, et al. Mortality, disability, and falls in older persons: the role of underlying disease and disability. Am J Public Health 1992; 82(2): 395-400.

[4] Perry BC. Falls among the elderly: A review of the methods and conclusions of epidemiologic studies. J Am Geriatr Soc 1982; 306 : 367-71.

[5] Sattin RW, Lambert H, DeVito CA, et al. The incidence of fall injury events among the elderly in a defined population. Am J Epidemiol 1990; 131(6): 1028-37.

[6] Yardley L, Smith H. A prospective study of the relationship between feared consequences of falling and avoidance of activity in community-living older people. Gerontologist 2002; 42(1): 17-23.

[7] Rapp K, Lamb SE, Buchele G, et al. Prevention of falls in nursing homes: subgroup analyses of a randomized fall prevention trial. J Am Geriatr Soc 2008; 56(6): 1092-7. 
[8] Costello E, Edelstein JE. Update on falls prevention for community-dwelling older adults: review of single and multifactorial intervention programs. J Rehab Res \& Dev 2008; 45(8): 1135-52.

[9] Tinetti ME, Speechley, Ginter SF. Risk factors for falls among elderly persons living in the community. N Eng J Med 1988; 319(26): 1701-7.

[10] Speechley M, Tinetti M. Assessment of risk and prevention of falls among elderly persons: role of the physiotherapist. Physiother Can 1990; 42: 75-9.

[11] Reed-Jones RJ, Solis GR, Lawson KA, Loya AM, Cude-Islas D, Berger CS. Vision and falls: a multidisciplinary review of the contributions of visual impairment to falls among older adults. Maturitas 2013; 75(1): 22-8.

[12] Honeycutt PH, Ramsey P. Factors contributing to falls in elderly men living in the community. Geriatric Nurs 2002; 23(5): 250-55.

[13] Patla AE, Frank JS, Winter DA. Balance control in the elderly: implications for clinical assessment and rehabilitation. Can J Public Health 1992; 83(Suppl 2): S29-33.

[14] Lord SR, Dayhew J, Howland A. Multifocal glasses impair edgecontrast sensitivity and depth perception and increase the risk of falls in older people. J Am Geriatr Soc 2002; 50(11): 1760-6.

[15] Joo JH, Lenze EJ, Mulsant BH, et al. Risk factors for falls during late-life depression. J Clin Psychiatry 2002; 63(10): 936-41.

[16] Richter M, Becker C, Seifert J, et al. Injury prevention in the elderly population. Unfallchirurg 2002; 105(12): 1076-87.

[17] Richardson JK. Factors associated with falls in older patients with diffuse polyneuropathy. J Am Geriatr Soc 2002; 50(11): 1767-73.

[18] Foley CJ, Wolf-Klein GP. Prevention of falls in the geriatric patient with osteoporosis. Clin Rheumatol Pract 1986; 4: 136-43.

[19] Northridge ME, Nevitt MC, Kelsey JL, Link B. Home hazards and falls in the elderly: the role of health and functional status. Am J Public Health 1995; 85(4): 509-15.

[20] Kellogg International Work Group on the Prevention of Falls by the Elderly. The prevention of falls in later life. Dan Med Bull 1986; 34(Suppl): 1-24.

[21] Stoddart H, Sharp D, Harvey I, et al. Falls and the use of health services in community living elderly people. $\mathrm{Br} \mathrm{J}$ Gen Practice 2002; 52(484): 923-5.

[22] Hughes M. Fall prevention and the National Service Framework. Nurs Stand 2002; 17(4): 33-8.

[23] Salonen L, Kivelä SL. Eye diseases and impaired vision as possible risk factors for recurrent falls in the aged: a systematic review. Curr Gerontol Geriatr Res 2012; 2012: 271481

[24] Gillespie LD, Gillespie WJ, Robertson MC, et al. Interventions for preventing falls in the elderly. Cochrane DataBase Syst Rev 2001; 3: CD000340

[25] Gillespie LD, Robertson MC, Gillespie WJ, et al. Interventions for preventing falls in older people living in the community. Cochrane Database Syst Rev. 2012; 9: CD007146.

[26] Cornillon E, Blanchon MA, Ramboatsisetraina $\mathrm{P}$, et al. Effectiveness of falls prevention strategies for elderly subjects who live in the community with performance assessment of physical activities (before-after). Ann Readapt Med Phys 2002; 45(5): 493504.

[27] Ray W, Griffen MR. Prescribed medications and the risk of falling. Top Geriatr Rehabil 1990; 5: 12-20.

[28] Tideiksaar R. Preventing falls: home hazard checklists to help older patients protect themselves. Geriatrics 1986; 41(5): 26-8.

[29] Newton M, Sanderson A. The effect of visual impairment on patients' falls risk. Nurs Older People 2013; 25(8): 16-21.

[30] Harwood RH. Visual problems and falls. Age Ageing 2001; 30(Suppl 4): 13-8.

[31] Legood R, Scuffham P, Cryer C. Are we blind to injuries in the visually impaired? A review of the literature. Inj Prev 2002; 8(2): $155-60$.

[32] Luukinen $\mathrm{H}$, Koski $\mathrm{K}$, Laippala $\mathrm{P}$, et al. Factors predicting fractures during falling impacts among home-dwelling older adults. J Am Geriatr Soc 1997; 45(11): 1302-9.

[33] Koski K, Luukinen $\mathrm{H}$, Laippala $\mathrm{P}$, et al. Risk factors for major injurious falls among the home-dwelling elderly by functional abilities. A prospective population-based study. Gerontol 1998; 44(4): 232-8.

[34] Grisso JA, Kelsey JL, Strom BL, et al. Risk factors for falls as a cause of hip fracture in women. The Northeast Hip Fracture Study Group. N Engl J Med. 1991; 324(19): 1326-31.
[35] Klein BE, Moss SE, Klein R, et al. Associations of visual function with physical outcomes and limitations 5 years later in an older population: the Beaver Dam eye study. Ophthalmology 2003; 110(4): 644-50.

[36] French DD, Margo CE, Tanna AP, et al. Associations of injurious falls and self-reported incapacities: analysis of the National Health Interview Survey. J Patient Saf 2014 Feb 27 [Epub ahead of print].

[37] Coleman AL, Stone K, Ewing SK, et al. Higher risk of multiple falls among elderly women who lose visual acuity. Ophthalmology 2004; 111(5): 857-62.

[38] Patino CM, McKean-Cowdin R, Azen SP, et al. Los Angeles Latino Eye Study Group. Central and peripheral visual impairment and the risk of falls and falls with injury. Ophthalmology 2010; 117(2): 199-206.

[39] Lord SR, Clark RD, Webster IW. Visual acuity and contrast sensitivity in relation to falls in an elderly population. Age Ageing 1991; 20(3): 175-81.

[40] Lord SR. Visual risk factors for falls in older people. Age Ageing 2006; 35(Suppl 2): ii42-5.

[41] Vale A, Buckley JG, Elliott DB. Gait alterations negotiating a raised surface induced by monocular blur. Optom Vis Sci 2008; 85(12): 1128-34

[42] Chapman GJ, Vale A, Buckley J, et al. Adaptive gait changes in long-term wearers of contact lens monovision correction. Ophthalmic Physiol Opt 2010; 30(3): 281-8.

[43] Lichtenstein MJ, Shields SL, Shiavi RG, Burger MC. Clinical determinants of biomechanics platform measures of balance in aged women. J Am Geriatr Soc 1988; 36(11): 996-1002.

[44] Ramulu PY, van Landingham SW, Massof RW, et al. Fear of falling and visual field loss from glaucoma. Ophthalmol 2012; 119(7): 1352-8.

[45] Johnson L, Buckley JG, Scally AJ, et al. Multifocal spectacles increase variability in toe clearance and risk of tripping in the elderly. Invest Ophthalmol Vis Sci 2007; 48(4): 1466-71.

[46] Tuunainen E, Rasku J, Jäntti P, et al. Risk factors of falls in community dwelling active elderly. Auris Nasus Larynx 2014; 41(1): 10-6.

[47] Glynn RJ, Seddon JM, Krug JH Jr, et al. Falls in elderly patients with glaucoma. Arch Ophthalmol 1991; 109(2): 205-10.

[48] Coleman AL, Cummings SR, Yu F, et al. Study Group of Osteoporotic Fractures. Binocular visual-field loss increases the risk of future falls in older white women. J Am Geriatr Soc 2007; 55(3): 357-64.

[49] Wood JM, Lacherez P, Black AA, et al. Risk of falls, injurious falls, and other injuries resulting from visual impairment among older adults with age-related macular degeneration. Invest Ophthalmol Vis Sci 2011; 52(8): 5088-92.

[50] Dhital A, Pey T, Stanford MR. Visual loss and falls: a review. Eye (Lond). 2010; 24(9): 1437-46.

[51] Felson DT, Anderson JJ, Hannan MT, et al. Impaired vision and hip fracture. The Framingham Study. J Am Geriatr Soc 1989; 37(6): 495-500.

[52] Klein BE, Klein R, Lee KE, et al. Performance-based and selfassessed measures of visual function as related to history of falls, hip fractures, and measured gait time. The Beaver Dam Eye Study. Ophthalmology 1998; 105(1): 160-4.

[53] Ivers RQ, Cumming RG, Mitchell $\mathrm{P}$, et al. Visual risk factors for hip fracture in older people. J Am Geriatr Soc 2003; 51(3): 356-63.

[54] Close J, Ellis M, Hooper R, et al. Prevention of falls in the elderly trial (PROFET): a randomised controlled trial. Lancet 1999; 353(9147): 93-7.

[55] Kantayaporn C. Fall with and without fracture in elderly: what's different? J Med Assoc Thai 2012; 95(Suppl 10): S109-12.

[56] Skalska A, Wizner B, Piotrowicz K, et al. The prevalence of falls and their relation to visual and hearing impairments among a nation-wide cohort of older Poles. Exp Gerontol. 2013; 48(2):1406.

[57] Nagamatsu LS, Munkacsy M, Liu-Ambrose T, et al. Altered visual-spatial attention to task-irrelevant information is associated with falls risk in older adults. Neuropsychologia 2013. pii: S00283932(13)00346-1.

[58] Källstrand-Ericson J, Hildingh C. Visual impairment and falls: a register study. J Clin Nurs. 2009; 18(3): 366-72.

[59] Campbell AJ, Sanderson G, Robertson MC. Poor vision and falls. BMJ 2010; 340: c2456. 
[60] Cumming RG, Ivers R, Clemson L, et al. Improving vision to prevent falls in frail older people: a randomized trial. J Am Geriatr Soc 2007; 55(2): 175-81.

[61] Abdelhafiz AH, Austin CA. Visual factors should be assessed in older people presenting with falls or hip fracture. Age Ageing 2003; 32(1): 26-30.

[62] Tinetti ME. Where is the vision for fall prevention? J Am Geriatr Soc. $2001 ; 49(5): 676-7$.

[63] Day L, Fildes B, Gordon I, Fitzharris M, et al. Randomised factorial trial of falls prevention among older people living in their own homes. BMJ 2002; 325(7356): 128.

[64] Swamy B, Cumming RG, Ivers R, et al. Vision screening for frail older people: a randomised trial. Br J Ophthalmol 2009; 93(6): 736-41.

[65] Day L, Trotter MJ, Hill KD, et al. Implementation of evidencebased falls prevention in clinical services for high-risk clients. J Eval Clin Pract 2014; 20(3): 255-9.

[66] Mikolaizak AS, Simpson PM, Tiedemann A, et al. Intervention to prevent further falls in older people who call an ambulance as a result of a fall: a protocol for the iPREFER randomised controlled trial. BMC Health Serv Res 2013; 13: 360.

[67] Clemson L, Cumming RG, Kendig H, et al. The effectiveness of a community-based program for reducing the incidence of falls in the elderly: a randomized trial. J Am Geriatr Soc 2004; 52(9): 1487-94.

[68] Lord SR, Tiedemann A, Chapman K, et al. The effect of an individualized fall prevention program on fall risk and falls in older people: a randomized, controlled trial. J Am Geriatr Soc 2005; 53(8): 1296-304

[69] Haran MJ, Cameron ID, Ivers RQ, et al. Effect on falls of providing single lens distance vision glasses to multifocal glasses wearers: VISIBLE randomised controlled trial. BMJ 2010; 340: c2265.

[70] Fitzharris MP, Day L, Lord SR, Gordon I, Fildes B. The Whitehorse NoFalls trial: effects on fall rates and injurious fall rates. Age Ageing 2010; 39(6): 728-33.

[71] Karlsson MK, Vonscheelov T, Karlsson C, et al. Prevention of falls in the elderly: a review. Scand J Public Health 2013; 41(5): 442.

[72] Laurent M, Thompson JA. The role of visual information in control of a constrained locomotor task. J Motor Behav 1988; 20, 17-37.

[73] Georgopoulos A P, Grillner S. (1989). Visuomotor coordination in reaching and locomotion. Science 1989; 245: 1209-110.

[74] Young WR, Hollands MA. Evidence for age-related decline in visuomotor function and reactive stepping adjustments. Gait Posture 2012; 36(3): 477-81.

[75] Willis JR, Vitale SE, Agrawal Y, et al. Visual impairment, uncorrected refractive error, and objectively measured balance in the United States. JAMA Ophthalmol 2013; 131(8): 1049-56.

[76] Barrett MM, Doheny EP, Setti A, et al. Reduced vision selectively impairs spatial updating in fall-prone older adults. Multisens Res 2013; 26(1-2): 69-94.

[77] Gibson J. Visually controlled locomotion and visual orientation in animals. Brit J Psychol 1958; 49(3): 182-94.

[78] Thompson JA. Is continuous visual monitoring necessary in visually guided locomotion? J Exp Psychol:Human Perc Perform 1983; 9: 427-43.

[79] Lee DN, Lishmann JR, Thompson JA. Regulation of human gait in long jumping. J Exp Psychol: Human Perc Perform 1982; 8: 44859.

[80] Patla AE. In search of laws for the visual control of locomotion: Some observations. J Exp Psychol: Human Perc Perform 1989; 15: 524-628.

[81] Patla A E, Robinson C, Samways M, et al. Visual control of step length during overground locomotion: Task-specific modulation of the locomotor synergy. J Expl Psychol: Human Perc Perform 1989; 15: $601-15$.

[82] Iinattiniemi S, Jokelainen J, Luukinen H. Falls risk among a very old home-dwelling population. Scand J Prim Health Care 2009; 27(1): 25-30.

[83] Assiante C, Amblard B, Carblanc A. Peripheral vision and dynamic equilibrium control in five to twelve year old children. In: Amblard B, Berthoz A, Clarac F, Eds. Posture and gait: Development adaptation and modulation. North Holland: Elsevier Science Publishers 1988; pp. 75-83.

[84] Black AA, Wood JM, Lovie-Kitchin JE. Inferior field loss increases rate of falls in older adults with glaucoma. Optom Vis Sci $2011 ; 88(11)$ : $1275-82$.
[85] Wu TY, Chie WC, Yang RS, et al. Risk factors for single and recurrent falls: a prospective study of falls in community dwelling seniors without cognitive impairment. Prev Med 2013; 57(5): 5117.

[86] Uemura K, Yamada M, Nagai K, et al. Impaired choice stepping in response to a visual-spatial attention demanding task among older adults at high risk of falling: a pilot study. Aging Clin Exp Res 2012; 24(4): 361-4.

[87] Timmis MA, Pardhan S. Patients with central visual field loss adopt a cautious gait strategy during tasks that present a high risk of falling. Invest Ophthalmol Vis Sci 2012; 53(7): 4120-9.

[88] Coleman AL. Sources of binocular suprathreshold visual field loss in a cohort of older women being followed for risk of falls (an American Ophthalmological Society thesis). Trans Am Ophthalmol Soc 2007; 105: 312-29.

[89] Davison J, Bond J, Dawson P, et al. Patients with recurrent falls attending Accident \& Emergency benefit from multifactorial intervention - a randomised controlled trial. Age Ageing 2005; 34(2): 162-8

[90] Seemongal-Dass RR, James TE, Atherley CE. Guidelines for prevention of falls in people aged over 65 . Guidelines should state that assessment of vision is important. BMJ 2001; 322(7285): 554.

[91] de Boer MR, Pluijm SM, Lips P, et al. Different aspects of visual impairment as risk factors for falls and fractures in older men and women. J Bone Miner Res 2004; 19(9): 1539-47.

[92] Bradley SM. Falls in older adults. Mt Sinai J Med. 2011; 78(4): 590-5.

[93] Chase CA, Mann K, Wasek S, Arbesman M. Systematic review of the effect of home modification and fall prevention programs on falls and the performance of community-dwelling older adults. Am J Occup Ther 2012; 66(3): 284-91.

[94] Waldron N, Hill AM, Barker A. Falls prevention in older adults assessment and management. Aust Fam Physician 2012; 41(12) 930-5.

[95] Tiedemann A, Sherrington C, Close JC, et al; Exercise and Sports Science Australia. Exercise and Sports Science Australia position statement on exercise and falls prevention in older people. J Sci Med Sport 2011; 14(6): 489-95.

[96] Chou R, Dana T, Bougatsos C. Screening for Visual Impairment in Older Adults: Systematic Review to Update the 1996 U.S Preventive Services Task Force Recommendation [Internet]. Rockville (MD): Agency for Healthcare Research and Quality (US); 2009 Jul. Available from http://www.ncbi.nlm.nih.gov/book S/NBK35192/

[97] Freeman EE, Muñoz B, Rubin G, et al. Visual field loss increases the risk of falls in older adults: the Salisbury eye evaluation. Invest Ophthalmol Vis Sci 2007; 48(10): 4445-50.

[98] Szabo SM, Janssen PA, Khan K, et al. Older women with agerelated macular degeneration have a greater risk of falls: a physiological profile assessment study. J Am Geriatr Soc 2008; 56(5): 800-7.

[99] Tran TH, Nguyen Van Nuoi D, Baiz H, Baglin G, Leduc JJ, Bulkaen H. [Visual impairment in elderly fallers]. J Fr Ophtalmol 2011; 34(10): 723-8

[100] Yip JL, Khawaja AP, Broadway D, et al. Visual acuity, selfreported vision and falls in the EPIC-Norfolk Eye study. Br J Ophthalmol 2014; 98(3): 377-82.

[101] Kulmala J, Viljanen A, Sipilä S, et al. Poor vision accompanied with other sensory impairments as a predictor of falls in older women. Age Ageing 2009; 38(2): 162-7.

[102] To KG, Meuleners LB, Fraser ML, et al. Prevalence and visual risk factors for falls in bilateral cataract patients in ho chi minh city, Vietnam. Ophthalmic Epidemiol 2014; 21(2): 79-85.

[103] Black AA, Wood JM, Lovie-Kitchin JE, et al. Visual impairment and postural sway among older adults with glaucoma. Optom Vis Sci 2008; 85(6): 489-97.

[104] Newell FN, Foran TG, Burke K, et al. Reduced vision impairs spatial cognition in fall-prone older adults. Res Pract in Visual Impairment Blindness 2011; 4: 103-11.

[105] Impaired vision linked to diminished balance. The vestibular system, which controls balance and may prevent falls, may be affected by vision. Duke Med Health News 2013; 19(9): 1-2.

[106] Keay L, Palagyi A, McCluskey P, et al. Falls in older people with Cataract, a longitudinal evaluation of impact and risk: the FOCUS study protocol. Inj Prev 2014; 20(4): e7 
[107] Steinman BA, Allen SM, Chen J, Pynoos J. Functional limitations as potential mediators of the effects of self-reported vision status on fall risk of older adults. J Aging Health 2014; [Epub ahead of print].

[108] Ellison AC, Campbell AJ, Robertson MC, Sanderson GF. Prismatic displacement effect of progressive multifocal glasses on reaction time and accuracy in elderly people. Clin Ophthalmol.2014; 8: 891902.

[109] Elliott DB. The Glenn A. Fry award lecture 2013: blurred vision, spectacle correction, and falls in older adults. Optom Vis Sci 2014; 91(6): 593-601.

[110] Adams T. Connecting falls to elder vision. Optom Vis Sci 2014; 91(6): 591-2.

[111] Barrett MM, Doheny EP, Setti A, et al. Reduced vision selectively impairs spatial updating in fall-prone older adults. Multisens Res 2013; 26(1-2): 69-94.

[112] Black AA, Kimlin JA, Wood JM. Stepping accuracy and visuomotor control among older adults: effect of target contrast and refractive blur. Ophthalmic Physiol Opt 2014; 34(4): 470-8.

[113] Meuleners LB, Fraser ML, Ng J, Morlet N. The impact of first- and second-eye cataract surgery on injurious falls that require hospitalisation: a whole-population study. Age Ageing 2014; 43(3): $341-6$
[114] Lord SR, Smith ST, Menant JC. Vision and falls in older people: risk factors and intervention strategies. Clin Geriatr Med 2010; 26(4): 569-81

[115] Källstrand-Eriksson J, Baigi A, Buer N, Hildingh C. Perceived vision-related quality of life and risk of falling among community living elderly people. Scand J Caring Sci 2013; 27(2): 433-9.

[116] Yoo IY. Recurrent falls among community-dwelling older Koreans: prevalence and multivariate risk factors. J Gerontol Nurs 2011; 37(9): 28-40.

[117] Rossat A, Fantino B, Nitenberg C, et al.Risk factors for falling in community-dwelling older adults: which of them are associated with the recurrence of falls? J Nutr Health Aging 2010; 14(9): 78791.

[118] Menant JC, St George RJ, Fitzpatrick RC, Lord SR. Impaired depth perception and restricted pitch head movement increase obstacle contacts when dual-tasking in older people. J Gerontol A Biol Sci Med Sci 2010; 65(7): 751-7.

[119] Ranaweera AD, Fonseka P, PattiyaArachchi A, Siribaddana SH Incidence and risk factors of falls among the elderly in the District of Colombo. Ceylon Med J 2013 ; 58(3): 100-6.

[120] Klein D, Rapp K, Küpper M, et al. A population-based intervention for the prevention of falls and fractures in home dwelling people 65 years and older in South Germany: protocol. JMIR Res Protoc 2014; 3(1): e19.

(C) Ray Marks; Licensee Bentham Open.

This is an open access article licensed under the terms of the Creative Commons Attribution Non-Commercial License (http://creativecommons.org/licenses/by$\mathrm{nc} / 3.0 /$ ) which permits unrestricted, non-commercial use, distribution and reproduction in any medium, provided the work is properly cited. 